\title{
A simulation investigation of performance of polymer injection in hydraulically fractured heterogeneous reservoirs
}

\author{
J. Abbasi ${ }^{1}$ B. Raji ${ }^{1}$ M. Riazi ${ }^{1} \cdot$ A. Kalantariasl ${ }^{2}$
}

Received: 22 May 2016/Accepted: 24 October 2016/Published online: 10 November 2016

(c) The Author(s) 2016. This article is published with open access at Springerlink.com

\begin{abstract}
Polymer flooding is a popular enhanced oil recovery method because of its impact on improvement of sweep efficiency. Polymers are non-Newtonian fluids with different behavior at different flow rates. At high shear rate, they reveal shear-thinning behavior, which is the apparent viscosity reduction by increasing shear rate. However, higher shear rate let them become dilatant. Consequently, an increase in shear rate contributes to increase in apparent viscosity and thus decreases the well injectivity of polymer. Hydraulic fracturing reduces mechanical shearing in the vicinity of the wellbore and plays an important role in feasibility of polymer flooding scenarios due to injectivity enhancement and lowering shear rate. A three-dimensional simulator was used to construct a synthetic model of the reservoir with no-flow boundary condition. Results show that induced hydraulic fractures improve recovery factor of homogeneous and heterogeneous reservoirs due to an increase in injectivity of polymer flooding, although in vertically heterogeneous reservoirs, induced fractures are not very effective. The results also show that the induced fractures are more successful in reservoirs with viscous oil.
\end{abstract}

Keywords Induced fractures · Polymer flooding · Well injectivity $\cdot$ Shear thickening

M. Riazi

mriazi@shirazu.ac.ir

1 Enhanced Oil Recovery Research Center, Department of Petroleum Engineering, School of Chemical and Petroleum Engineering, Shiraz University, Molla Sadra St., P.O. Box: 7134851154, Shiraz, Fars, Iran

2 Department of Petroleum Engineering, School of Chemical and Petroleum Engineering, Shiraz University, Shiraz, Iran

\section{Introduction}

Without a shadow of a doubt, global energy demand is increasing annually and enhancing oil recovery (EOR) from mature reservoirs is of crucial importance. Waterflooding is a popular technique to increase recovery in a candidate oil reservoir; afterward, chemical EOR is a reasonable option to increase recovery further. Polymer flooding is a favorable chemical EOR method due to its impact on sweep efficiency (Standnes and Skjevrak 2014). Vertical heterogeneity may cause incomplete sweep through waterflooding, and polymer fluid is used to drive water within bypassed regions (Needham and Doe 1987). Generally, polymers are responsible for water increasing viscosity and reduction in its relative permeability (Sheng et al. 2015). Therefore, injection of a high-viscosity polymeric fluid leads to mobility ratio improvement, viscous fingering reduction and consequently increasing areal sweep efficiency (Pye 1964; Sandiford 1964).

A challenging problem through polymer flooding is the impact of shear rate on viscosity of polymeric fluid that is undoubtedly of concern for injectivity issues. At high shear rate, it reveals shear-thinning behavior (i.e., apparent viscosity reduction by increasing shear rate). However, higher shear rate leads to become dilatant; consequently, an increase in shear rate contributes to increase in the apparent viscosity (Chauveteau 1982).

Many investigators studied shear-thinning and shearthickening behavior of two types of applicable polymer in chemical EOR operations, which are categorized into synthetic polymers (partially hydrolyzed polyacrylamide, HPAM) and biopolymers (xanthan gum). As polymeric fluid flows in porous media at high velocities, HPAM molecules do not have adequate time to become compatible with the flow (Delshad et al. 2008); consequently, the apparent viscosity increases and will be seen as shear- 
thickening behavior. At low velocities, both xanthan and HPAM show shear-thinning behavior (Cannella et al. 1988; Seright 2010) and fluid viscosity decreases as a result of velocity or shear rate increase. For mean and high velocities, xanthan still has shear thinning (Seright 2010), while HPAM viscosity increases with velocity, leading to shear rate increase that is called shear thickening (Hirasaki and Pope 1974; Masuda et al. 1992; Smith 1970).

Injectivity declines with respect to time due to the fact that viscosity of polymeric fluid changes during flooding process. There are a couple of mitigation actions to prevent injectivity declines including alteration of injection rate, polymer solution concentration or fracturing injection (Glasbergen et al. 2015). Injection under fracturing condition is a useful action that initiates polymer flood above formation parting pressure (FPP), which creates induced fractures contributing to injectivity increment. Calculations of injectivity for both below and above FFP were studied by Prasad Saripalli et al. (1999) and Rousseau et al. (2007).

In some field projects under polymer flooding, it was observed that actual polymer injectivity was higher than that of the expected one, even higher than water injectivity (Alsaadi et al. 2012; Morel et al. 2012). A likely reason is that injection pressure greater than the formation fracturing pressure would be more possible during polymer flooding (Seright 2010), and consequently, induced fractures are generated and propagated during polymer flooding (van den Hoek et al. 2009). Fracture size and direction have an important effect on waterflooding and enhancement of oil recovery (Chaban et al. 2009; Gadde and Sharma 2001; Van den Hoek 2004; van den
Hoek et al. 2009), especially for those reservoirs containing multilayered formations (Lee et al. 2011).

Induced hydraulic fractures are essential to be investigated in order to improve the feasibility of polymer flooding processes due to increasing injectivity and lowering shear rate. Therefore, in this study, the effect of induced fractures on injectivity of polymer injection wells using two different homogeneous and heterogeneous reservoir models is investigated. Firstly, the simulation model is briefly discussed. Then, the results of different scenarios are described. The impact of hydraulic fracture is completely presented in detail for homogeneous and heterogeneous reservoirs through areal and vertical heterogeneities. Afterward, the effect of induced hydraulic fractures on polymer flooding recovery factor is studied for two reservoirs having high- and low-viscosity oil types.

\section{Model description}

A three-dimensional simulator was used to construct a synthetic model of the reservoir with no-flow boundary conditions. Water production from aquifer is negligible. A sensitivity analysis was conducted, and optimum number of the grids in $\mathrm{x}$ and $\mathrm{y}$ directions determined to reduce numerical dispersion. In addition, a logarithmic gridding has been used which enables tracking fluid flow around the wells more accurately. Permeability values in the heterogeneous model have been allocated randomly ranging from 1 to $20 \mathrm{md}$. Figure 1a, b shows areal and vertical heterogeneous models.
Fig. 1 Static models, a permeability differences in areal heterogeneous model, b permeability differences in vertically heterogeneous model. c A simple schematic for the gridding algorithm, location of wells and fracture dimension and orientation
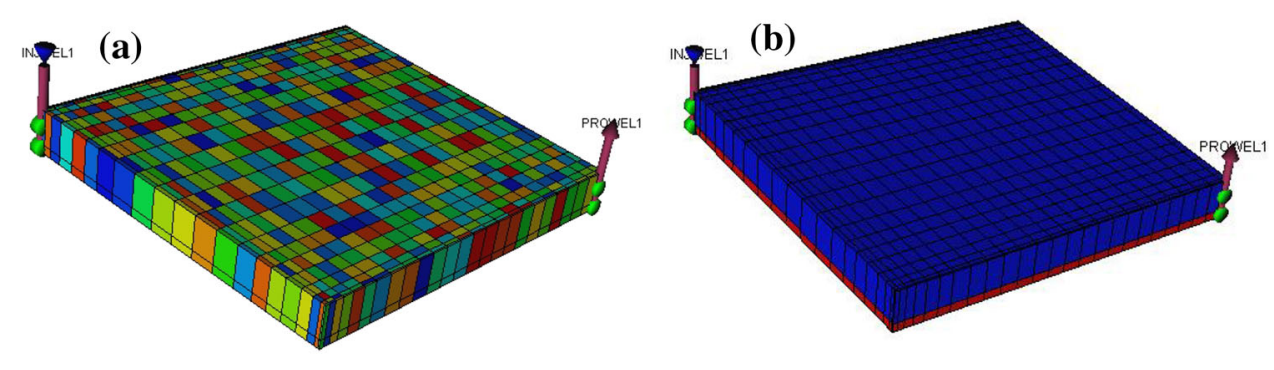

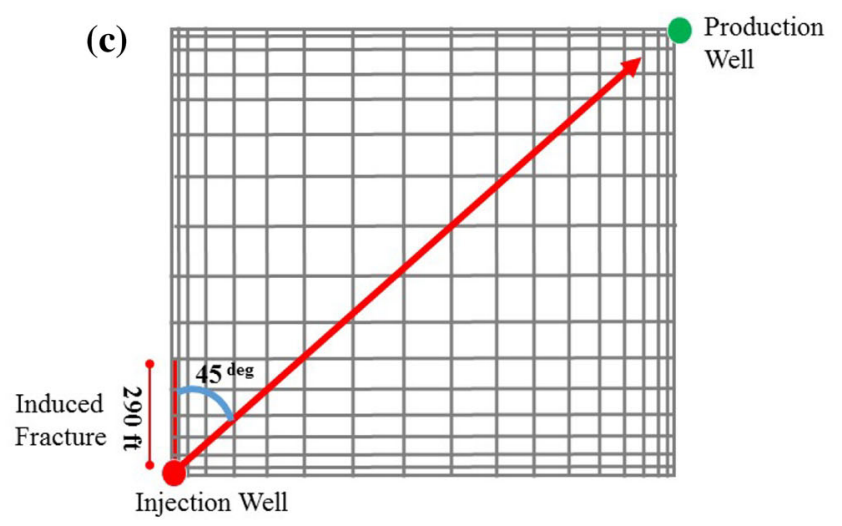


Table 1 Main reservoir and fracture properties

\begin{tabular}{llll}
\hline Porosity (-) & 0.09 & Fracture porosity (-) & 0.4 \\
Number of grids in $X$ direction & 25 & Fracture permeability (d) & 20 \\
Number of grids in $Y$ direction & 25 & Height of induced fracture (ft) & 100 \\
Number of grids in $Z$ direction & 2 & Half-length of induced fracture (ft) & 290 \\
Simulation approach & Black oil & Width of induced fracture (ft) & 0.07 \\
Initial pressure (psia) & 4000 & Water viscosity (cp) at $4000 \mathrm{psia}$ & 0.8 \\
Well diameter (ft.) & 0.583 & Rock compressibility (1/psia) at $4000 \mathrm{psia}$ & $4 \times 10^{-6}$ \\
Initial formation volume factor (bbl/STB) & 1.2175 & Pay zone height (ft) & 100 \\
\hline
\end{tabular}

Table 2 Heterogeneous model permeability description

Average horizontal permeability (md) 10.420

Average vertical permeability (md)

Standard deviation of horizontal permeability (md) $\quad 5.754$

Lowest horizontal permeability (md)

Highest horizontal permeability (md)

1

20

Table 1 shows the common properties of all models. It also presents properties of induced fracture. Table 2 shows permeability characteristics of the heterogeneous model. Figure 1c is a simple schematic for the fracture dimensions and its direction with respect to the main flow line where the fracture is modeled explicitly (discrete fractures). The permeability of fracture is assumed to be identical in all directions. In reality, fracture properties may change due to stress, particle clogging, operational problems, etc., which can be implemented in a complex simulation approach. This paper compares performance of induced fracture based on average values. Therefore, fracture properties are assumed to be constant.

Viscosities of reservoir fluid and polymeric solution at different pressures and polymer concentrations are shown in Fig. 2a, b, respectively. In this work, assume that the reservoir fluid is dead oil, and during pressure reduction, no gas will be released from oil. Figure 3 illustrates polymer viscosity versus time at different injection rates at which

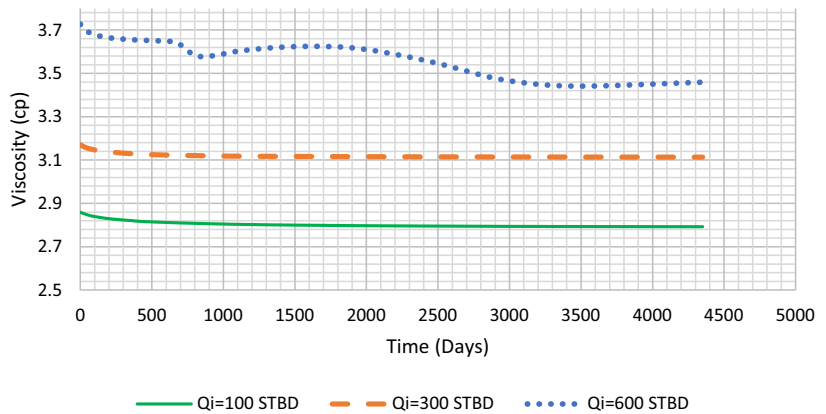

Fig. 3 Viscosity of polymeric solution at different injection rates

increasing shear rate (i.e., flow rate) increases the viscosity of the polymeric solution. Hershel-Buckley model has been used to relate viscosity of the polymeric solution to its shear rate. As it is shown in Eq. 1, by setting suitable calibration parameters, it is possible to make the polymeric fluid behave as a shear-thickening fluid (Mullineux 2008). $y=y_{o}+K \dot{y}^{n}$

where $y_{o}$ is the yield stress of the polymeric solution, $K$ is the consistency index, and $n$ is the flow behavior index. For $n<1$, the fluid is shear thinning, whereas for $n>1$, the fluid is shear thickening. If $n=1$ and $y_{o}=0$, this model is reduced to the Newtonian fluid. Also if $y<y_{o}$, the model behaves as solid. Here $n$ is defined to be 1.414 so that fluid behaves as a shear-thickening fluid.
Fig. 2 a Reservoir fluid viscosity at different pressures for both high- and low-viscosity scenarios. b The viscosity of polymeric solution at different polymer concentrations (a)

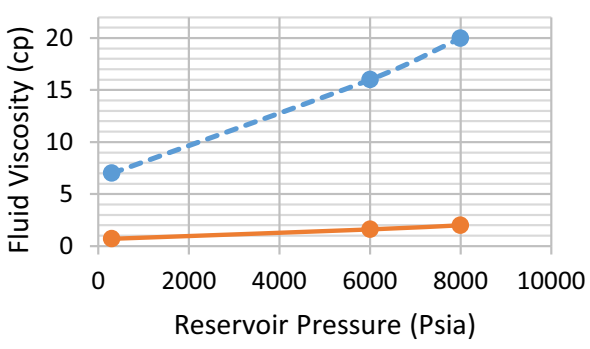

- - High Viscosity _— Low Viscosity (b)

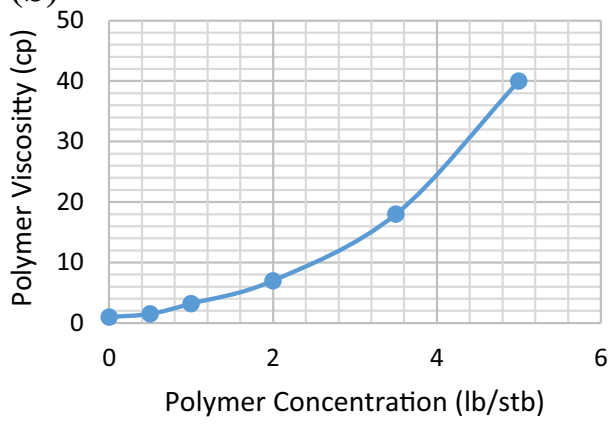




\section{Results and discussion}

High polymer viscosity decreases well injectivity and postpones oil recovery. As Eq. 2 indicates, well injectivity is defined as the ratio of the injection rate and pressure difference between well and reservoir (Van Wingen 1949).

Injectivity index $=\frac{Q_{\mathrm{i}}}{\Delta P}$

where $Q_{\mathrm{i}}$ is the injection rate and $\Delta P$ is the pressure drop between injector and average reservoir pressure.

As Fig. 3 shows, the shear-thickening behavior of polymers during injection increases the polymer viscosity by increasing injection rate.

\section{Homogeneous reservoir}

The model has been simulated at different polymer concentrations to compare non-fractured and fractured wells by assuming well injection rate of 400 STBD and maximum bottom-hole pressure (BHP) of 6700 psia. At first, the effect of induced fractures in a low permeable homogeneous reservoir is investigated. Horizontal and vertical permeabilities are assumed to be 10 and $3 \mathrm{md}$, respectively. As can be seen from Fig. 4, when there is no fracture around well, optimized recovery factor (i.e., 73\%) is obtained at polymer concentration of $0.6 \mathrm{lb} / \mathrm{STB}$. With induced fracture, recovery factor increases up to $75 \%$ at polymer concentration of $1.0 \mathrm{lb} / \mathrm{STB}$. Thus, it can be stated that the presence of fracture would increase recovery factor more than $2.45 \%$ since more viscous polymer could be injected. Fracture injectivity improvement factor (FIIF), in this case, is more than 0.86. Here, FIIF is defined as follows:

$\mathrm{FIIF}=\left(\frac{\left(R F_{\mathrm{opc}}\right)_{\text {fractured well }}-R F_{\mathrm{wf}_{\text {non-fractured well }}}}{\left(R F_{\mathrm{opc}}\right)_{\text {non-fractured well }}-R F_{\mathrm{wf}_{\text {non-fractured well }}}}\right)-1$

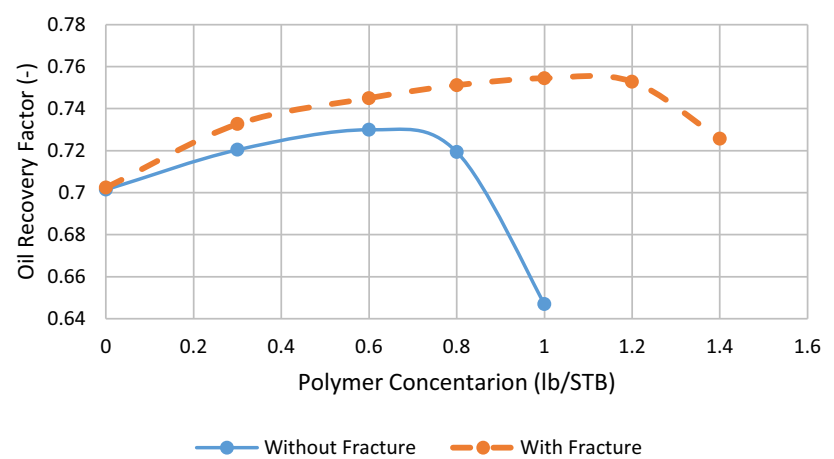

Fig. 4 Field oil recovery versus polymer concentration for the nonfractured and fractured injection well in homogeneous model where opc stands for optimum polymer concentration and wf stands for waterflooding or injection without any polymer concentration. Hence, FIIF indicates that hydraulic fractures could improve the effect of polymer flooding on increasing oil recovery factor around $86 \%$ compared to polymer flooding from a non-fractured well in this homogeneous reservoir. It was observed that at a constant injection rate, increasing polymer concentration up to the optimized one would increase oil recovery factor. After increasing polymer viscosity, well injectivity and recovery factor reduce because of additional pressure drop near the wellbore. In fact, when the viscosity of injecting fluid increases, the differential pressure required to keep injection rate constant increases. However, when an induced fracture is propagated around the well, both optimized polymer concentration and recovery factor increase.

As it can be seen from Fig. 4, the presence of induced fracture increases recovery factor in all polymer concentrations. It indicates that at high polymer concentrations (more than its optimum value), injection well cannot be performed at its objective rate and its bottom-hole pressure reaches to its maximum possible value. While the effect of polymer degradation has been neglected, induced fracture can only increase the recovery factor by lowering differential pressure required to inject at a constant rate. Figure 5 compares recovery factor and well injectivity of injection well for non-fractured and fractured well versus time at the optimized polymer concentration. This figure shows that fracture increases both oil recovery factor and well injectivity index.

\section{Areal heterogeneous reservoir}

In this part of paper, the effect of fracture on recovery factor of a reservoir with areal heterogeneity and average horizontal permeability of $10.42 \mathrm{md}$ with standard deviation of $5.75 \mathrm{md}$ (Table 2) is investigated. As Fig. 6 shows, in a heterogeneous reservoir with a non-fractured well for polymer concentration of $0.30 \mathrm{lb} / \mathrm{stb}$, maximum recovery factor is 0.67 . The reservoir recovery factor increases to 0.73 for polymer concentration of $0.8 \mathrm{lb} / \mathrm{stb}$ in the presence of the fracture. In fact, fracture increases recovery factor of the heterogeneous reservoir by $5.72 \%$ by improving the well injectivity and the optimized polymer concentration. It can be concluded that induced fractures in heterogeneous reservoirs can be more effective than that in homogeneous ones. Indeed, induced fractures improve FIIF more than $529 \%$. It should be mentioned that it depends on the properties of the zones where the injector well has been drilled because well injectivity is dependent on the properties of the completed area. 


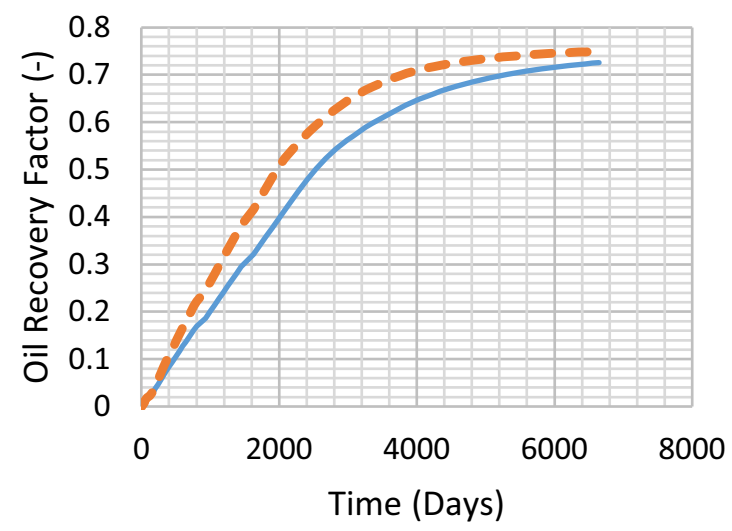

Without Fracture $-\infty$ With Fracture

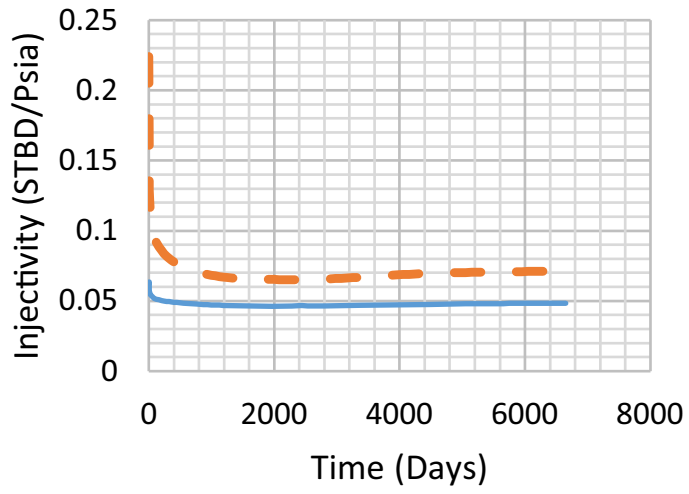

Without Fracture - With Fracture

Fig. 5 Field oil recovery and well injectivity index for injection well at optimized polymer concentration versus time

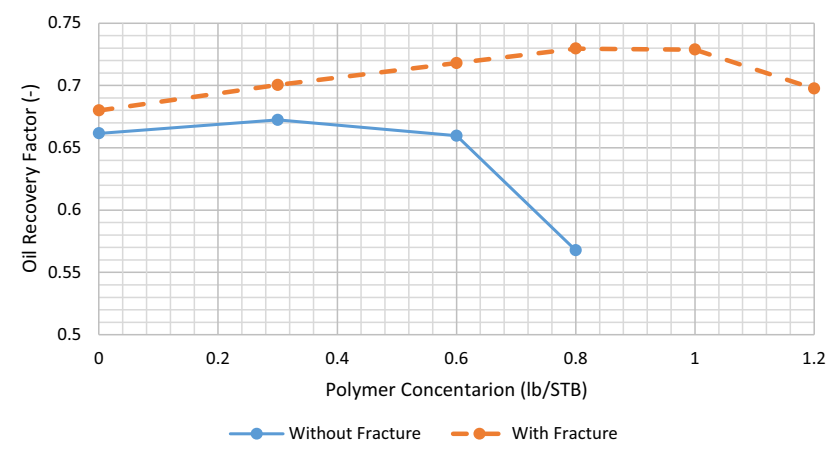

Fig. 6 Field oil recovery versus polymer concentration for nonfractured and fractured injection well in areal heterogeneous model

Figure 7 shows the effect of induced fracture on recovery factor of the reservoir and its effect on well injectivity index of the injection well in optimum polymer concentrations of $0.3 \mathrm{lb} / \mathrm{stb}$ in the non-fractured case and
0.8 for induced fractured case. This figure shows that induced fracture increases recovery factor of the reservoir by increasing optimum polymer concentration. Also induced hydraulically fracture increases well injectivity by decreasing pressure difference between well bottom hole and the reservoir.

\section{Vertically heterogeneous reservoir}

In reservoirs containing significant vertical heterogeneities, polymeric fluid diminishes the bypassing of low-permeability layers and improves vertical sweep efficiency. In this case, an areal homogeneous but vertically heterogeneous reservoir (two layers) has been defined. Reservoir horizontal permeabilities and layer thickness are assumed to be $10,100 \mathrm{md}$ and $80,20 \mathrm{ft}$, respectively. As Fig. 8 shows, polymer flooding enhances recovery factor from 0.58 up to more than 0.73 by lowering oil bypassing. It is (a)

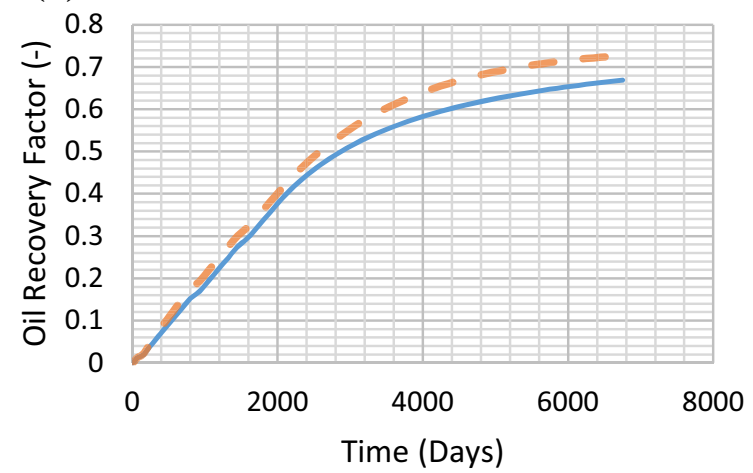

Without Fracture -- With Fracture (b)

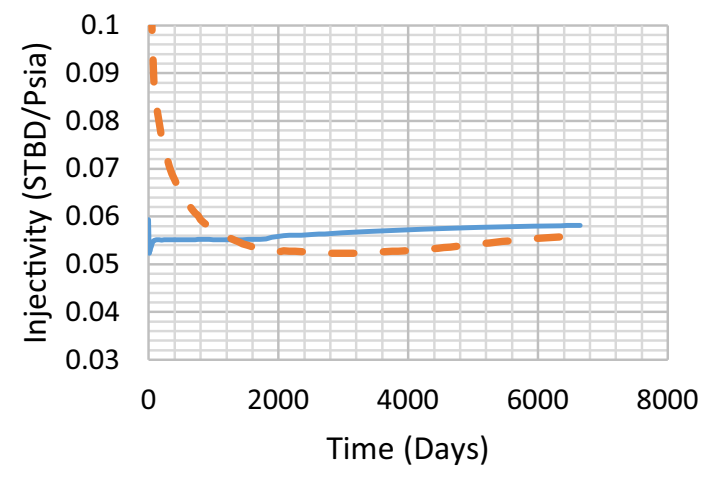

Without Fracture - With Fracture

Fig. 7 a Field oil recovery versus time for fractured and non-fractured wells in their optimized polymer concentration. b Effect of fracture in injectivity index of the injection well

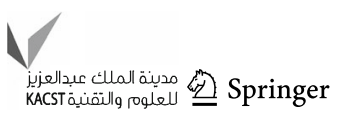




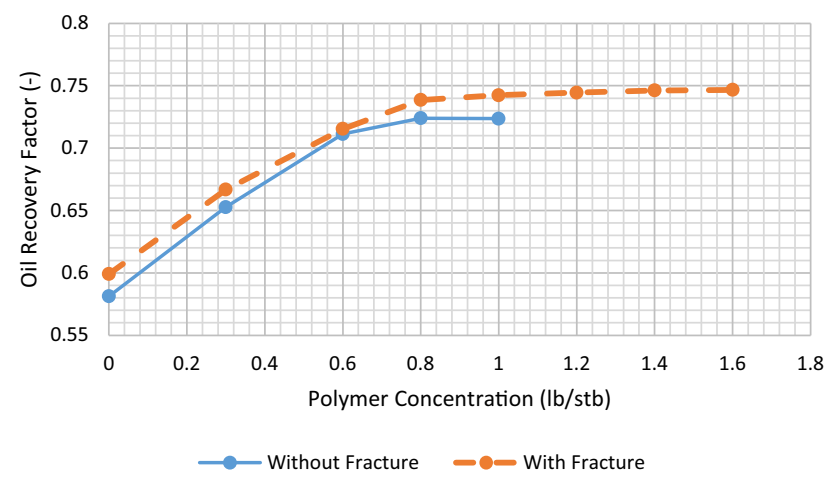

Fig. 8 Field oil recovery versus polymer concentration for nonfractured and fractured injection well in vertically heterogeneous model

because of high vertical heterogeneity and cross-flow in high-permeability layer that reduces vertical sweep efficiency in which polymer injection improves vertical sweep efficiency. Polymer flooding efficiency, in this case, is over $15 \%$ that is much more than that of the vertically homogeneous case. However, because of problems in polymer injectivity due to the high viscosity of polymeric solution, proper injection criteria are hard to be continued. In the non-fractured well, the maximum recovery factor is 0.724 at a polymer concentration of 0.8 , but in fractured well, it increases to more than 0.738 to an optimized polymer concentration of $0.8 \mathrm{lb} / \mathrm{stb}$. In more concentrated polymer solutions, the recovery factor of the reservoir increases slightly that shows that more polymer concentrations are not economical. On the other hand, in cases where polymer adsorption to rock surfaces is a great concern, induced fracture makes it possible to inject with more concentrations without any injection problems and reduces project failure risk because of decreasing polymer concentration in areas far from the injector well. Induced fractures in this model do not play important role in increasing recovery factor, since in highly vertical heterogeneous models, usually wells do not suffer from low injectivity index because of their connections to high permeable streaks and layers. In fact, induced fractures can only improve FIIF by $14.3 \%$. Nevertheless, induced fracture makes polymer flooding less sensitive to polymer concentration and reduces probability polymer flooding failure. Figure 9 shows the effect of induced fracture on recovery factor of reservoir and injectivity index of the injection well for this heterogeneous reservoir. Although the viscosity of polymer does not increase significantly as a result of high injection velocity, it significantly improves polymer flooding efficiency.

\section{Effect of viscosity and induced fracture}

Reservoir fluid viscosity can affect the feasibility of polymer flooding. Unfavorable mobility ratios in reservoirs with moderate or high oil viscosities under water injection methods are still an open challenge in the petroleum industry (Zechner et al. 2015). In this section, a high-permeability reservoir (horizontal and vertical permeability of 60 and $10 \mathrm{md}$ ) with two high- and low-viscosity oil types has been assumed. Effect of induced fracture on oil recovery performance has been studied for both low- and high-viscosity reservoir fluids. Figure 10 represents that induced fracture has positive effect for the reservoir having viscous oil, whereas, in low-viscosity case it is not effective or perhaps it may have even some negligible negative effects.

Table 3 shows extremum of data presented in Fig. 10. It is concluded that fracture can be more useful in reservoirs

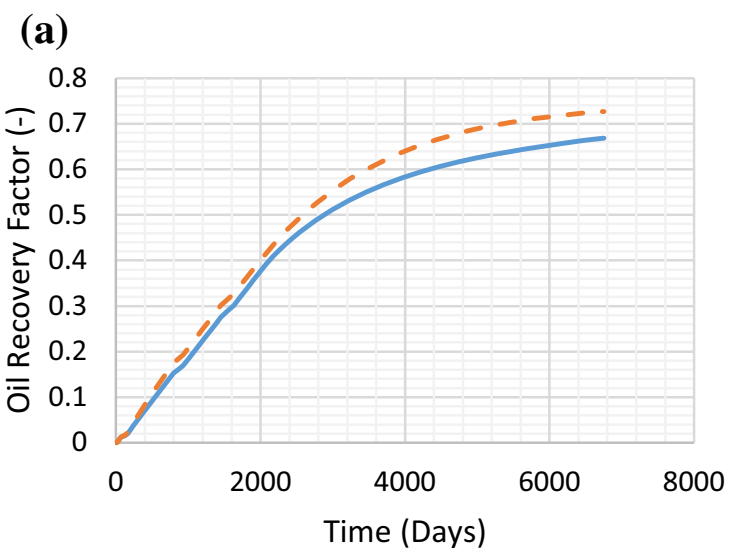

Without Fracture $\quad-\quad-$ With Fracture (b)

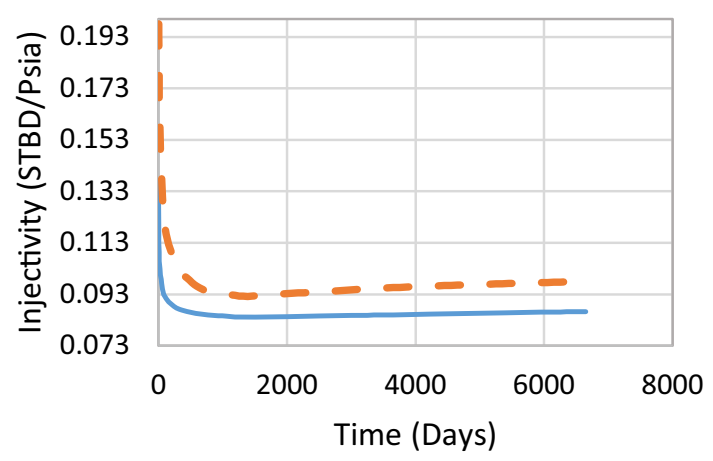

Wothout Fracture -- With Fracture

Fig. 9 a Field oil recovery versus time for fractured and non-fractured wells at the optimized polymer concentration. b Effect of fracture on injectivity index of the injection well 


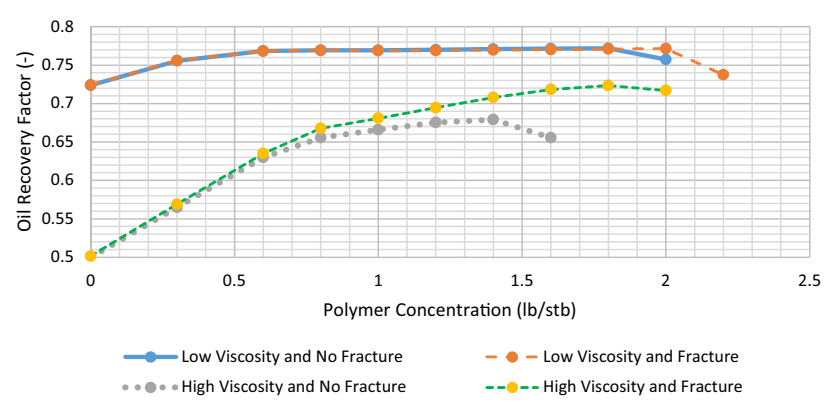

Fig. 10 Comparing the effect of induced fracture on recovery factor of two models with high-viscosity and low-viscosity fluid properties

Table 3 Effect of fracture on high- and low-viscosity models

\begin{tabular}{lll}
\hline & $\begin{array}{l}\text { High } \\
\text { viscosity }\end{array}$ & $\begin{array}{l}\text { Low } \\
\text { viscosity }\end{array}$ \\
\hline $\begin{array}{l}\text { Optimized polymer concentration without } \\
\text { fracture }\left(\mathrm{lb} / \mathrm{ft}^{3}\right)\end{array}$ & 1.4 & 1.8 \\
$\begin{array}{l}\text { Optimized recovery factor without fracture }(-) \\
\begin{array}{l}\text { Optimized polymer concentration with } \\
\text { fracture }\left(\mathrm{lb} / \mathrm{ft}^{3}\right)\end{array}\end{array}$ & 0.67 & 0.77 \\
$\begin{array}{l}\text { Optimized recovery factor with } \\
\text { fracture }(-)\end{array}$ & 0.72 & 2.0 \\
$\begin{array}{l}\text { Effect of fracture to increase } \\
\text { recovery factor }(-)\end{array}$ & 0.04731 & Negligible \\
\hline
\end{tabular}

containing high-viscosity fluids because of challenges of injection in reservoirs containing these kinds of fluids.

In this paper, constant induced fracture properties were assumed. However, induced fracture initiation and propagation are a dynamic process, and several reservoir-related and operational parameters can affect its properties and consequently its performance. Coupling dynamic fracture initiation and propagation and polymer injection performance can be done with more details as a separate work. Main goal of this study was to investigate and compare the effect of fixed fracture (after initiation and propagation stage) on polymer flooding efficiency in heterogeneous reservoirs (well injectivity, recovery factor, etc.) as a basic study.

\section{Conclusions}

The effect of induced fractures on polymeric injectivity and oil recovery of the specified reservoir was investigated. Due to low injectivity index of polymer injection wells, induced fractures are highly efficient in homogeneous reservoirs. Based on the results of this study, the following conclusions can be drawn.

- The favorable case for induced fractures is areal heterogeneous reservoirs. In this case and for the reservoir and fracture properties used in this paper, FIIF process increased by more than $529 \%$.

- In vertically heterogeneous reservoirs, the impact of induced fractures on polymer flooding efficiency (FIIF) is about $14.3 \%$. Although high permeable streaks and layers improve injectivity index, this injection wells normally do not suffer from low injectivity problems. However, induced fractures make polymer flooding projects less sensitive to polymer injection problems like reducing the polymer concentration due to polymer adsorption on the rock surface and improving success probability of polymer flooding.

- Induced fractures are more useful in high-viscosity oil reservoirs. Induced fractures have negative effects on recovery factor of reservoirs containing low-viscosity fluids.

Open Access This article is distributed under the terms of the Creative Commons Attribution 4.0 International License (http:// creativecommons.org/licenses/by/4.0/), which permits unrestricted use, distribution, and reproduction in any medium, provided you give appropriate credit to the original author(s) and the source, provide a link to the Creative Commons license, and indicate if changes were made.

\section{References}

Al-saadi FS, Al-amri BA, Nofli A, Mubarak S, Van Wunnik JNM, Jaspers HF, Al Harthi S, Shuaili K, Cherukupalli PK, Chakravarthi R (2012) Polymer flooding in a large field in South Oman-initial results and future plans. In: SPE EOR conference at oil and gas West Asia. Society of Petroleum Engineers

Cannella WJ, Huh C, Seright RS (1988) Prediction of xanthan rheology in porous media. SPE Annu Tech Conf Exhib Proc. doi: $10.2523 / 18089-M S$

Chaban FR, Llc G, Sharma MM, Suri A (2009) SPE 124857 a unified, multidisciplinary approach to the planning and design of deepwater waterflooding projects. SPE Annu. Tech. doi:10. 2118/124857-MS

Chauveteau G (1982) Rodlike polymer solution flow through fine pores: influence of pore size on rheological behavior. J Rheol 26:111-142

Delshad M, Kim DH, Magbagbeola OA, Huh C, Pope GA, Tarahhom F (2008) Mechanistic interpretation and utilization of viscoelastic behavior of polymer solutions for improved polymer-flood efficiency. In: SPE symposium on improved oil recovery. Society of Petroleum Engineers

Gadde PB, Sharma MM (2001) Growing injection well fractures and their impact on waterflood performance. In: SPE annual technical conference and exhibition. Society of Petroleum Engineers

Glasbergen G, Wever D, Keijzer E, Farajzadeh R (2015) Injectivity loss in polymer floods: causes, preventions and mitigations. In: SPE Kuwait oil and gas show and conference. Society of Petroleum Engineers

Hirasaki GJ, Pope GA (1974) Analysis of factors influencing mobility and adsorption in the flow of polymer solution through porous media. Soc Pet Eng J 14:337-346 
Lee K, Huh C, Sharma MM (2011) Impact of fractures growth on well injectivity and reservoir sweep during waterflood and chemical EOR processes. In: SPE annual technical conference and exhibition. Society of Petroleum Engineers

Masuda Y, Tang K-C, Miyazawa M, Tanaka S (1992) 1D simulation of polymer flooding including the viscoelastic effect of polymer solution. SPE Reserv Eng 7:247-252

Morel DC, Vert M, Jouenne S, Gauchet R, Bouger Y (2012) First polymer injection in deep offshore field Angola: recent advances in the Dalia/Camelia field case. Oil Gas Facil 1:43-52

Mullineux G (2008) Non-linear least squares fitting of coefficients in the Herschel-Bulkley model. Appl Math Model 32:2538-2551

Needham RB, Doe PH (1987) Polymer flooding review. J Pet Technol 39:1-503

Prasad Saripalli K, Bryant SL, Sharma MM (1999) Role of fracture face and formation plugging in injection well fracturing and injectivity decline. In: SPE/EPA exploration and production environmental conference, pp 415-430

Pye DJ (1964) Improved secondary recovery by control of water mobility. J Pet Technol 16:911-916

Rousseau D, Latifa H, Nabzar L (2007) PWRI-induced injectivity decline: new insights on in-depth particle deposition mechanisms. In: European formation damage conference. Society of Petroleum Engineers

Sandiford BB (1964) Laboratory and field studies of water floods using polymer solutions to increase oil recoveries. J Pet Technol 16:917-922
Seright R (2010) Potential for polymer flooding reservoirs with viscous oils. SPE Reserv Eval Eng 13:24-28. doi:10.2118/ 129899-PA

Sheng JJ, Leonhardt B, Azri N (2015) Status of polymer-flooding technology. J Can Pet Technol 54:116-126. doi:10.2118/ 174541-PA

Smith FW (1970) The behavior of partially hydrolyzed polyacrylamide solutions in porous media. J Pet Technol 22:148-156

Standnes DC, Skjevrak I (2014) Literature review of implemented polymer field projects. J Pet Sci Eng 122:761-775

Van den Hoek PJ (2004) Impact of induced fractures on sweep and reservoir management in pattern floods. In: SPE annual technical conference and exhibition. Society of Petroleum Engineers

van den Hoek PJ, Al-Masfry RA, Zwarts D, Jansen J-D, Hustedt B, Van Schijndel L (2009) Optimizing recovery for waterflooding under dynamic induced fracturing conditions. SPE Reserv Eval Eng 12:671-682

Van Wingen N (1949) Injectivity indices-their prediction and determination. In: Drilling and production practice. American Petroleum Institute

Zechner M, Clemens T, Suri A, Sharma MM (2015) Simulation of polymer injection under fracturing conditions-an injectivity pilot in the Matzen field, Austria. SPE Reserv Eval Eng 18:236-249 